\title{
Foreword to WOSSPA2013 Proceedings
}

These Proceedings are the outcome of an event, WoSSPA'2013, held at Zeralda, nearby Algiers. Themain scientific and technical organizers of this event, in addition to myself (from Qatar University and University of Queensland, Australia), came from different parts of the world, including "EcolePolytechnique" of Algiers, University of Rijeka, Croatia and many others in Canada, USA, Ireland and France with the main local contributors being the ViceChair and the TPC liaison, both from CDTA ("Centre de Développement des Technologies Avancées"). CDTA is located in Algiers and it was the local co-organizer and main sponsor of the event.

This meeting represented the 27th Anniversary of WoSSPA, andthe second time itwas hosted in an African country. This achievement followed the successful organization of ISSPA'2007, WoSPA'2008 held in Sharjah (United Arab Emirates) and WoSSPA'2011 held in Tipaza, Algeria as well as the more recent organization of ISSPA2012 in Montreal, Canada. Most earlier eventsin the 1980s, 90s and 2000s were held in Australia apart from a joint event organized in Malaysia in 2005. The name of the event was then WoSPA (Worshop on Signal Processing and its Applications). The word "Systems" in the title was added in the year 2011.

The technical review process for this event was both systematic and thorough. All submitted papers were reviewed by at least three independent reviewers, with some papers getting up to 8 independent reviews. We had opened 16 regular tracks and 7 special sessions for submission. We received 232 papersfrom which 173 papers were reviewed and 69 were withdrawn or rejected without review. From the 173 reviewed papers, 93 were accepted, and 80 rejected, resulting in an acceptance rate of 54\%.The accepted papers were organized in 8 poster session and 7 oral sessions. In addition, the program was enhanced by 6 half-day Tutorial presentations and 3 Plenary presentations (see inside for details).

As for all the previous events, the technical program and Proceedingsprioritized some particular topics: Biomedical Research, Signal Processing for Communications and Radar Signal Processing as well as other multi-disciplinary research. The selection of these topics is mostly driven by the needs and interests of the local Researchers as well as the hot topics in the field.

As of now, with this workshop, we will have organized four high level events (including ISSPA'2007 and WoSPA'2008, and WoSSPA'2011) in the field of Signal Processing in the Middle East \& North Africa region (MENA) since I moved full-time to this region from Australia to help link a focus on research activities with Community Service. Our studies found that local universities can make a significant leap in the field of Signal Processing should they connect with expatriate researchers working in overseas universities. To make this link productive, it was desirable to define clear objectives and efficient strategies. Organizing WoSSPA'2013 is part of this plan; it continues the same tradition of high-quality, broad international participation in all areas of Signal Processing. It strives to take advantage of local expertise to define new multi-disciplinary research directions that lead to significant innovation for the benefit of the local, Arab, African and international community at large. In particular, local researchers participating at WoSSPA'2013would be able to mingle freely with overseas delegates without the hassles in trying to get a visa for events organized in an overseas destination with restrictive visa requirements.

I personally thank all the contributors, and especially the international ones, for their participation to this event and hope that they benefitted from discussions through their interactions with local researchers. I am convinced that WoSSPA'2013was profitable for all 
delegates and will fully contribute in promoting world standards in local research teams so as to meet the challenges ahead and helping to become some of the top notch research teams in the region. Indeed, a desired outcome of such scientific meetingsisto help regional emerging countrieslink with cutting-edge international research conducted in more developed countries. This allows building new networks linking researchers from these different regions innew collaborations. At a more individual level, international delegates could identify opportunities available for research locally, given that the host country Algeria was, in 2013, ranked No.14 worldwide in terms of cash reserves, with a significant new focus on the funding of research programs; the event also allowed local researchers will be able to establish new connections.

As the founder of both ISSPA and WoSPA, as the former founder and Director for 15 years of the Signal Processing Research Centre in Australia, and as the former Dean of ECUoS, this event is also part of my personal strategy which is to serve the Community and ensure that my work will leave a useful legacy both internationally and locally.

This event could proceed because many colleagues teamed up tomake this event successful.This included of course, the local co-organizer and main sponsor of this event, BrahimBouzouia, Director of CDTA,the Wosspa2013 Vice-Chair and Research Director, DjamelBouchafra, the TPC co-chairs, Adel Belouchrani and Victor Sucic, the Tutorial Chair, Karim Abed-Meraim, as well as the CDTA-TPC liaison, Amine Bouabdallah who worked tirelessly to make this event a success. In addition, the event benefitted considerably from the Steering Committee members who provided timely advice (Mohamed Cheriet, Abbes Amira and Sebti Foufou), andthemain technical Track chairs ( Tiago Falk, Ervin Sejdic and Haikal El-Abed).

I would like to thank everybody else who was involved and contributed in a way or another to the success of this event and to these Proceedings. The complete list of contributors appears in the list of Committees.

Prof Boualem Boashash

WoSSPA 2013 General Chair Chairman of the Steering Committee

School of Medicine, University of Queensland, Brisbane, Australia

Dept of Electrical Engineering, Qatar University, Doha, Qatar.

(prepared in Doha, Qatar, 2013) 